\title{
La poesía como lección de historia, Matei Vişniec, «En la mesa con Marx» («La masă cu Marx»)
}

\author{
Angelica LAMBRU \\ Universidad de Valencia \\ angelica.lambru@gmail.com
}

\begin{abstract}
RESUMEN
Tras una sucinta presentación de las principales coordenadas del exilio literario rumano, el artículo se propone revelar algunos aspectos de la originalidad poética de Matei Vişniec, escritor rumano de expresión francesa, que se define como un «exiliado afortunado». El poema propuesto, «En la mesa con Marx» («La masă cu Marx»), representa el eje del libro con el mismo título, publicado en Rumanía, en 2011. Su lectura explícitamente política lo conecta con otro texto que circuló como manifiesto anti-comunista en los años previos a la caída del régimen comunista, el poema titulado «El velero» («Corabia»). Parábola de la complicidad y de la culpa colectiva, «En la mesa con Marx» es una poética lección de historia sobre elecciones sociales erradas, con desenlaces fatales para la humanidad.
\end{abstract}

Palabras clave: exilio, multiculturalidad, bilingüismo, culpa, comunismo, historia.

\section{Poetry as a historical lesson. Matei Vişniec, «At the table with Marx» («La masă cu Marx»)}

\begin{abstract}
After a brief presentation describing the main traits of the literary Romanian exile, this article aims to reveal some aspects of Matei Vişniec's poetical originality, a Romanian francophone writer who defines himself as a «lucky exiled man». The poem we've chosen, «At the table with Marx» («La masă cu Marx»), involves the main line of the book with the same title that was published in Romania in 2011. His explicitly political regard relates him to another text that circulated as an anti-communist manifesto during the previous years of the communist dictature fall: the well-known poem entitled «The sailing ship» («Corabia»). A parable of complicity and colective guiltiness, «At the table with Marx» is a lyrical lesson of history over wrong social choices, that fatally impacted on the whole mankind.
\end{abstract}

Keywords: exile, multiculturalism, bilingualism, guilt, communism, history.

Exiliado en París, en los años 80, Matei Vişniec es el único escritor rumano que define su exilio como «afortunado». Entre todas las categorías negativas que motivan, describen y estructuran el exilio político (Paul Goma (1997: 123), exiliado tam- 
bién en París, opinaba que «El exilio modifica, moldea, mutila a veces» ${ }^{1}$ ), el filósofo del Cenáculo de Lunes desliza una positiva, afirmando que nada más llegar a París, se sintió «feliz como un dios» (Vişniec 2007). La periodista y escritora Monica Lovinescu, una de las figuras más importantes del exilio rumano en Francia, proponía emplear el concepto de exilio en plural, observando que hay tantos exilios como personas, motivaciones y épocas. Desde luego, las reiteradas confesiones del «escritor rumano de expresión francesa» (Vişniec 2007) configuran un mapa de un destino literario prodigioso.

Los exégetas identifican tres grandes etapas del exilio literario rumano. La primera abarca los años 40 y 50 y es de procedencia conservadora. Se trata de simpatizantes de las tendencias de derechas, de monárquicos, de diplomáticos o intelectuales como Monica Lovinescu, Virgil Ierunca, Ştefan Baciu, Alexandru y George Ciorănescu, que intuyeron los cambios drásticos que iban a ser introducidos por el bloque comunista. Entre los primeros destacan Mircea Eliade, Eugen Ionescu, Emil Cioran, Constantin Virgil Gheorghiu, Vintilă Horia, Aron Cotruş, Pamfil Şeicaru, George Uscătescu.

La etapa de los años 60 y 70 incluye a escritores que, en su gran mayoría, conectan el período literario de entreguerras con la cultura universal contemporánea. Son escritores que, decepcionados por el desenlace de las ilusorias aperturas políticas del final de los años 60, eligen el camino del exilio. Son intelectuales de gran valor como Dumitru Țepeneag, Ilie Constantin, Paul Goma, Sorin Alexandrescu, Matei Călinescu, Virgil Nemoianu, Ion Negoiţescu, Gabriela Melinescu, Virgil Tănase, Ioan Petru Culianu, Sanda Golopenţia, Ion Vianu.

La última etapa, de los años 80 , corresponde a los más crueles años de la dictadura comunista e incluye escritores cuyo destino fue la capital francesa. Virgil Tănase resume perfectamente aquella realidad (Tănase 1996: 33): «Para los rumanos, el centro del mundo era París». Nombres como Norman Manea, Ion Caraion, Alexandru Papilian, Dorin Tudoran, Matei Vişniec, Bujor Nedelcovici, Nicolae Balotă, Al. Raicu, Mircea Iorgulescu representan la «tercera ola» del exilio rumano.

Precisamente porque salió de Rumanía a finales de los años 80 -concretamente en septiembre de 1987- Matei Vişniec no sintió el exilio como una experiencia agobiante, sino liberadora: «En 1987, en septiembre, cuando me fui a París con visa de turista, no se veía ningún indicio de la sumersión final. Parecía que todo iba a seguir igual, indefinidamente» $(2007)^{2}$. Vişniec encarna la figura del preexiliado: antes de salir de las fronteras geográficas, él ya había salido de sus coordenadas socio-políticas. En una entrevista, rememorando sus años de docente en un pueblecito perdido en las llanuras centrales del país, el escritor cuenta la anécdota significativa del perro que encontró caído en un pozo abandonado y al que le fue imposible salvar. No en el camino de Damasco, sino en el de Bărăgan, Matei Vişniec tuvo la revelación de la gran semejanza que había entre la situación de aquel desdichado perro y

\footnotetext{
1 «Exilul modifică, modelează, mutilează uneori».

2 «În 1987, în septembrie, când am plecat la Paris cu viză de turist, nu se vedea nicio urmă de scufundare definitivă. Mi se părea că totul va continua la fel, la nesfârşit».
} 
la suya. Aunque lo oyeran, nadie podía ayudarlo. Entonces pensó por primera vez en salir del país.

Como joven escritor, perteneció a la resistencia cultural anti-comunista. Las representaciones de su obra El apuntador del miedo (Sufleorul fricii) fueron prohibidas y su poema «El velero» («Corabia») circuló como manifiesto entre los miembros de la resistencia universitaria. De hecho, constituyó una de las razones por la cual el Cenáculo de Lunes fue cerrado.

El tren que lo llevó desde la Estación del Norte de Bucarest hasta la Estación del Este de París, en septiembre de 1987, tuvo un doble destino: geográfico e iniciático, porque el escritor se proponía viajar a «su patria mental». Se dirigía hacia la capital de Francia como un héroe hacia un territorio mítico conocido de oídas, arduamente anhelado. Una vez allí, experimentó una felicidad indescriptible, porque, según confiesa, «Me hallaba en mi patria mental, en una proyección que había enriquecido con mis lecturas de tantos años y cuando llegué allí todo me era conocido» ${ }^{3}$ (2007).

Es imprescindible apuntar desde el principio la gran laboriosidad de Matei Vişniec: es un escritor histriónico. En este mismo instante es muy probable que lance en alguna parte del mundo una obra nueva de teatro o una novela. Parafraseando la célebre frase de Terencio, nada de lo histórico le es extraño. Sus obras reflejan los grandes conflictos contemporáneos, el autor está siempre al pie de la noticia y eso se debe a su oficio de redactor en Radio France Internacionale. El escritor cura a través de la literatura las heridas del periodista, testigo de sucesivas catástrofes mundiales. Tampoco abandonó nunca la poesía, su Penélope, como la nombraba acertadamente el crítico literario Alex Ştefănescu (2001). Subyace formalmente en cada obra suya, él mismo se define como un dramaturgo poeta.

Otra de las particularidades definitorias de Matei Vişniec como escritor es su faceta de auto-traductor. Tras años de duro y constante trabajo de aprendizaje del francés, el dramaturgo afinó su bilingüismo hasta utilizarlo como un instrumento de escritura. Empezó traduciendo sus obras escritas en rumano (que su padre le enviaba desde Rumanía, una a una, dentro de las cartas), y llegó, años después, a emprender el viaje de vuelta, para traducir a su idioma materno las obras redactadas directamente en francés. Mantiene con los dos idiomas una relación única y original. Para el teatro, la disciplina del francés, que le enseñó a concentrarse sobre el valor del sonido de una palabra. Para la prosa y la poesía, el rumano, cuya belleza redescubrió al empezar a escribir en francés. Al tópico que encierra la recurrente pregunta que le da a elegir entre las dos lenguas, Matei Vişniec contesta con auténtica sabiduría: "Rumanía me dio las raíces y Francia, las alas» $(2007)^{4}$. En el panorama actual de la multiculturalidad, Matei Vişniec es un escritor único, un personaje de corte mitológico; nada más y nada menos que un gigante árbol alado que cubre con sus alas toda la literatura que cabe entre Rădăuţi (su ciudad natal) y París.

\footnotetext{
3 «Eram, ca să zic aşa, în patria mea mentală, într-o proiecţie pe care o îmbogăţisem cu lecturile mele de ani şi ani de zile, şi când am ajuns acolo totul îmi era cunoscut».

4 «România mi-a dat rădăcini, iar Franța mi-a dat aripi».
} 
La poesía de Matei Vişniec tiene siempre en cuenta al lector-espectador. Fluye como un río hacia una única desembocadura -la mente del receptor-, otorga al acto de contar una dimensión ontológica. Es estructuralmente comunicativa y la razón de este rasgo esencial no proviene de la impronta que tal vez puedan dejar los mecanismos de la literatura dramática que hizo del escritor de origen rumano un autor universal. Puede que sea justo al revés: que el poeta, cual filósofo, escriba con el fin de provocar a sus semejantes, con sus herramientas para la interpretación del mundo. Lo hace con total serenidad e irónica confianza, abriéndose en canal, confesando «pecados históricos» en nombre de toda una comunidad, sacrificándose con una finalidad catártica. Enseña una lección, igual que un maestro socrático (en los poemas de juventud, Sócrates es convertido en personaje poético, un dios cuyas apariciones ejercitan un poder devastador sobre el poeta y su universo).

«En la mesa con Marx» es una pequeña obra en cuatro capítulos, más un epílogo, incluida en el libro de poemas con el mismo título. Proponemos su lectura como un poema teatral en cuatro actos, al que se le añade el epílogo como final. Se trata de una escenificación poética remarcable de lo que significó el comunismo como «nuevo orden del mundo». Es un poema sobre la culpa colectiva y su expiación. Escrito en primera persona del plural, imagina una metafórica mesa que los países del Este compartieron, tras la Segunda Guerra Mundial, con Marx, Engels, Lenin y Stalin. De hecho, «la devoración» es uno de los temas fundamentales de la literatura de Vişniec, con todos sus componentes: el roer, la masticación, la deglución, que se prestan tan bien a los finos absurdos del texto. Sus matices, sus variantes, la implicación zoomórfica funden lo fantástico y lo absurdo en creaciones de seres únicos, monstruos que solo la mente humana es capaz de imaginar y cuya manipulación a menudo se vuelve en su contra.

El autor muestra el comunismo como un inmenso banquete en que la historia participa como un degradado personaje:

Habíamos comido como cerdos, con ganas, con bocas ávidas

de salsas y sabores

teníamos las barrigas llenas y los ojos turbios de saciedad

y un ligero vaho se desprendía del mantel, las migas echaban

humo

los vasos vacíos gorgoteaban, los cuchillos clavados en los panecillos y

las albóndigas

vibraban suavemente prolongando la memoria de la mano

olía a sangre y a carne picada, a vinagre y a piel

chamuscada

a platos relamidos y a sudor

estábamos orgullosos de nosotros tras lo ocurrido

la historia se había sentado con nosotros a la mesa y ahora bailaba

descalza

encima de los añicos de los vasos rotos

estábamos orgullosos de nosotros mismos, aunque un poco cansados 
y justo entonces se oyó la pregunta:

¿Y AHORA QUIÉN LAVA LOS PLATOS? (Vişniec 2011: 43) ${ }^{5}$

El poema es predominantemente visual y describe gradualmente un cuadro apocalíptico: los cuatro artífices del comunismo se convierten en polifemos en cuya mirada se ve reflejado el personaje-narrador («el último en llegar, [...] que había comido/de hecho, menos que nadie, más bien por cortesía» (Vişniec 2011: 43)) ${ }^{6}$ :

miré su ojo - Marx, Engels, Lenin y Stalin

tenían, de hecho,

un solo ojo, aposentado sobre la torreta de un tanque, un ojo

gigante como un faro

que giraba 360 grados a cada movimiento

de la burguesía. (Vişniec 2011: 43) ${ }^{7}$

La ironía va de la mano del lenguaje coloquial («te envía Lenin a por sal, / no te queda otra, corres hasta el horizonte y traes sal» (vv. 43-44) y constituye un fuerte potenciador del absurdo: siendo «el más joven», el último comensal debe obedecer las órdenes de sus «mayores» y caminar descalzo «por el mantel de la historia» (v.51). Mientras «los patriarcas» hacen la sobremesa (Marx y Engels se adormecen en los sillones, Lenin se toma su té y Stalin se fuma su pipa), «el aprendiz» (que confiesa «que cuenta deprisa y que debía haber empezado por el final» (vv. 58-59) debe enterrar a cien millones de muertos hasta la hora de la cena. Y como herramientas, solo dispone de una hoz y un martillo.

Fregar los platos del banquete supone para el anónimo invitado (el hombre llegado por casualidad al lugar equivocado, que se ve arrastrado por «el mantel de la historia» (v. 51), donde, paradójicamente, solo quedan las huellas de sus pasos) asumir la carga de enterrar los cuerpos de los compañeros con los que compartió «la fosa común» (v. 75) y cantó «canciones de libertad» (v. 86). Se trata de la velada culpa de la complicidad criminal extendida como una sombra sobre todos los que «han comido con Marx hasta los 30 años» (v.66).

no debía haber compartido con ellos el mismo mantel

no debía haber compartido con ellos el mismo pan y la misma sal

5 «Mîncaserăm ca porcii, cu poftă, cu gurile avide /de sosuri şi arome, / aveam burţile pline şi ochii / spălăciţi de saţietate / un abur uşor se ridica de pe faţa de masă, firimiturile / fumegau / paharele golite gîlgîiau, cuţitele înfipte în chifle şi chiftele /vibrau uşor prelungind memoria mîinii / mirosea a sînge şi a carne tocată, a oţet şi a piele pîrlită / a farfurii linse şi a sudoare / eram mîndri de noi în urma celor întîmplate /istoria stătuse cu noi la masă şi acum dansa cu picioarele goale / peste cioburile paharelor sparte / eram mîndri de noi, deşi puţin obosiţi / şi chiar atunci se auzi întrebarea: /ŞI ACUM CINE SPALĂ VASELE?»

${ }^{6}$ «[...] ultimul venit, eu care mîncasem / de fapt cel mai puţin, mai mult din politeţe?».

7 «m-am uitat în ochiul lor - Marx, Engels, Lenin şi Stalin / aveau de fapt / un singur ochi aşezat pe turela unui tanc, un ochi / uriaş ca un far/ care se rotea cu 360 de grade la orice mişcare/ a burgheziei». 
la misma garrafa con agua y la misma botella de vino no debía haber sido el primero en desearles que aproveche, pero tuve hambre. (Vişniec 2011: 48) ${ }^{8}$

Los cuatros anfitriones tienen sus papeles bien asignados. Hay una gradación del efecto que ejercen sobre su invitado: mientras Marx solo sirve sopa (plato fácil de digerir) y Engels, la col estofada, Lenin corta la carne (en su gesto hay una clara sugestión caníbal) y Stalin lo ensucia todo:
y más que nada, no habría debido sentarme justo enfrente de
Stalin
Stalin, cuando come, salpica horriblemente
ahora apesto todo a sopa, mi pelo está lleno de trozos de
carne
irrumpidos de la boca de Stalin. (Vişniec 2011: 48) ${ }^{9}$

El epílogo resuelve el conflicto en plano fantástico y ofrece un desenlace inesperado, el final «con el que debía haber empezado» el personaje y que lo cambia todo, situándolo en el momento de una reencarnación aplazada.
Una buena noticia: mi nacimiento será aplazado
ya no seré el que habría tenido que ser
eso es seguro, estoy borracho de felicidad
nada de lo que estuve a punto de vivir será vivencia
tendré otro pasado y otro futuro
tendré otra relación con Dios, con el mal y con
el bien
perderé en otros juegos, me enamoraré de otras mujeres
quizá ya no sea hombre
quizá viva yo también el misterio del parto
no sabía que era posible, pero
mira, en el instante de la muerte todo es posible. (Vişniec 2011: 49) ${ }^{10}$

Despojada de ornamentos elocuentes, la lección de historia es brutal: ante la alternativa de «sentarte en la mesa con Marx» es preferible no venir al mundo. Se trata de una manera muy propia de la generación poética de los 80 de expresar el

\footnotetext{
8 «nu trebuia să mănînc pe aceeaşi faţă de masă cu ei /nu trebuia să împart cu ei aceeaşi pîine şi aceeaşi sare / aceeaşi carafă cu apă şi aceeaşi sticlă de vin /nu trebuia să le urez primul poftă bună, dar mi-a fost foame».

9 «şi mai ales n-ar fii trebuit să mă aşez chiar în faţa lui Stalin /Stalin, cînd mănîncă, stropeşte îngrozitor / acum miros tot a supă, părul meu e plin de bucăţi de carne ţîş̧ite din gura lui Stalin».

10 «O veste bună: naşterea mea va fi amînată / nu voi mai fi ce era sa fiu / iată un lucru sigur, sunt beat de fericire / nimic din ce era să traiesc nu va mai fi trăire / voi avea un alt trecut şi un alt viitor / voi avea un alt raport cu Dumnezeu, cu răul şi cu binele / voi pierde la alte jocuri, mă voi îndrăgosti de alte femei /şi poate că nu voi mai fi bărbat /poate că voi trăi şi eu misterul naşterii / nu ştiam că se poate dar / iată în clipa morţii totul e posibil».
} 
abismal infortunio de haber nacido. No debemos olvidar que Vişniec, igual que Cioran, al que conoció y convirtió en personaje en una excepcional obra de teatro («Buhardilla con vistas a la muerte» - «Mansardă cu vedere spre moarte»-), es, al fin y al cabo, un escritor rumano.

Debido al momento histórico y al contexto geopolítico de su formación, la literatura del dramaturgo rumano contemporáneo más internacional está impregnada de referencias implícitas a la guerra. En gran parte de su obra, los conflictos armados que sacudieron el siglo XX configuran un territorio literario aparte, con estructura y leyes propias. Como gran artesano del absurdo, Matei Vişniec encontró en la alineación de la Segunda Guerra Mundial y en sus consecuencias aterradoras el espacio artístico ideal para el teatro-denuncia. Tal vez su obra «Historia del comunismo contada para los enfermos mentales ${ }^{11}$, incluida en el libro El Proceso del comunismo a través del teatro ${ }^{12}$, sea la máxima expresión dramática de su compromiso con las víctimas del comunismo, tal como lo demuestra una dedicatoria escueta pero totalizadora: «Obra dedicada a Daniil Harms y a todos los escritores fallecidos en las prisiones del poder» (Vişniec 2012: 15).

\section{Referencias bibliográficas}

BEHRING, Eva (2001): Scriitori români din exil 1945- 1989. O perspectivă istorico-literară. Bucureşti: Editura Fundaţiei Culturale Române.

GoMA, Paul (1997): Jurnal pe sărite. București: Editura Nemira.

ŞTEFăNESCU, Alex. (2001): «Penelopa lui Matei Vişniec». România literară 14 [en línea]. En: http://www.romlit.ro/penelopa_lui_matei_viniec [19/02/2015].

TĂNASE, Virgil (1996): România mea. Bucureşti: Editura Didactică şi Pedagogică.

VIŞNIEC, Matei (2007): «Am fost fericit ca un zeu». Agonia 2 [en línea]. En: http://www.poezie.ro/index.php/press/1738056/Am_fost_fericit._Ca_un_zeu [03/03/2016].

- (2011): La masă cu Marx. Bucureşti: Editura Cartea Românească.

- (2012): Procesul comunismului prin teatru. București: Editura Cartea Românească.

11 «Istoria comunismului povestită pentru bolnavii mintali», en Vişniec 2012: 15-80.

12 Procesul comunismului prin teatru. 